\title{
Austrian firearm legislation and its effects on suicide and homicide mortality: A natural quasi-experiment amidst the global economic crisis
}

\author{
Daniel König ${ }^{\mathrm{a}}$, Patrick Swoboda ${ }^{\mathrm{a}}$, Robert J. Cramer ${ }^{\mathrm{b}}$, Christoph Krall $^{\mathrm{c}}$, Vita Postuvan ${ }^{\mathrm{d}}$, \\ Nestor D. Kapusta ${ }^{\mathrm{e}, *}$

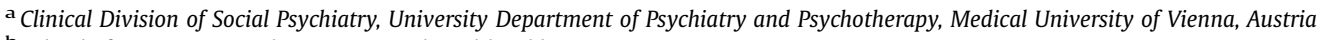 \\ ${ }^{\mathrm{b}}$ School of Community and Environmental Health, Old Dominion University, USA \\ ' Center for Medical Statistics, Informatics, and Intelligent Systems, Section for Medical Statistics, Medical University of Vienna, Austria \\ d Slovene Centre for Suicide Research, Andreij Marusic Insitute, University of Primorska, Slovenia \\ e Suicide Research Group, University Department of Psychoanalysis and Psychotherapy, Medical University of Vienna, Austria
}

\section{A R T I C L E I N F O}

\section{Article history:}

Received 27 February 2018

Received in revised form 24 April 2018

Accepted 25 April 2018

Available online 25 May 2018

\section{Keywords:}

Suicide

Homicide

Firearms

Epidemiology

Socioeconomics

\begin{abstract}
A B S T R A C T
Background: Restriction of access to suicide methods has been shown to effectively reduce suicide mortality rates.

Aims: To examine how the global economic crisis of 2008 and the firearm legislation reform of 1997 affected suicide and homicide mortality rate within Austria.

Methods: Official data for the years 1985-2016 for firearm certificates, suicide, homicide, unemployment rates and alcohol consumption were examined using auto regressive error and Poisson regression models.

Results: Firearm certificates, total suicide mortality rate, suicide and homicides by firearms, and the fraction of firearm suicides/homicides among all suicides/homicides decreased after the firearm legislation reform in 1997. However, significant trend changes can be observed after 2008. The availability of firearm certificates significantly increased and was accompanied by significant changes in trends of firearm suicide and homicide rates. Concurrently, the total suicide mortality rate in 2008, for the first time since 1985 , stopped its decreasing trend. While the total homicide rate further decreased, the fraction of firearm homicides among all homicides significantly increased.

Conclusion: The initially preventative effect of the firearm legislation reform in Austria in 1997 seems to have been counteracted by the global economic downturn of 2008. Increased firearm availability was associated with corresponding increases in both firearm suicide and firearm homicide mortality. Restrictive firearm legislation should be an imperative part of a country's suicide prevention programme. Although firearm legislation reform may have long-lasting effects, societal changes may facilitate compensatory firearm acquisitions and thus counteract preventive efforts, calling in turn again for adapted counter-measures.
\end{abstract}

(ㄷ) 2018 Elsevier Masson SAS. All rights reserved.

\section{Introduction}

The firearm availability hypothesis suggests that reduction of firearm availability may prevent suicides. The evidence for its cogency is documented by three major study types: First, crosssectional ecological studies show both an association between regional firearm availability and firearm deaths, as well as an

\footnotetext{
* Corresponding author.

E-mail addresses: Daniel.koenig@meduniwien.ac.at (D. König), Nestor.kapusta@meduiniwien.ac.at (N.D. Kapusta).
}

association between the strictness of regional firearm legislation and corresponding regional firearm mortality [1-3]. Second, longitudinal studies show that changes in firearm availability over time are associated with corresponding changes in firearm deaths [4]. Third, quasi-experimental longitudinal studies examining the effects of firearm legislation strengthening or other interventions aiming at the reduction of availability show corresponding declines of firearm related deaths after the intervention [5-9].

The aim of this study was to follow-up our previous study on the effects of the 1997 firearm legislation in Austria, which examined the time period between 1985 and 2005 [9]. Following 
that period, global societal changes were observable: The financial [10] and the refugee [11] crises both increased perceived threats in parts of the population [12], yielding media reports on increases in firearm possession [13]. Given that the developments after 2008 had a societal impact, we hypothesized a significant increase in (a) firearm availability and simultaneous and significant increases in (b) firearm suicide and homicide rates in Austria.

\section{Materials and methods}

We expanded our previous longitudinal approach [9] and examined suicide and homicide rates in Austria recorded between the years 1985 and 2016.

Firearm legislation in Austria

A Firearm certificate needs to be applied for at the local authorities and grants permission to the applicant of owning a registered and non-concealed firearm. The 1997 legislation reform added a number of prerequisites necessary before obtaining a firearm certificate: 1) Background checks (no convictions for serious offences or multiple minor offences registered); 2) passing a psychological test; 3 ) installation of safe storage for firearm and ammunition; 4) completing a course on safe firearm handling as well as storage; 5 ) being at least 20 years old; 6) applicants need to provide proof of danger to their life and need to argue that the use of firearms would be an adequate response. Only after a firearm certificate is granted by the local authorities, a firearm can be purchased and registered. Several weapons are banned from the citizenry (e.g. military style rifles, hand-grenades, pump-guns, any concealed weapon and brass knuckles).

\subsection{Data collection}

For the period of interest, 1985-2016, data on firearm certificates were obtained from the Ministry of the Interior. For the same time period data on population size, unemployment rates, alcohol consumption in litres of pure alcohol per capita, as well as the number of suicides, firearm suicides and firearm homicides (coded according to ICD-9 or ICD-10 respectively), were obtained from Statistics Austria. Data on total homicides encompass all convictions for both, murder and man-slaughter and were retrieved from Statistics Austria. For comparative reasons, we followed the same data acquisition methodology used in a previous report [9].

\subsection{Statistical analysis}

To assess the effect of the firearm legislation reform enacted in 1997 and possible effects of the economic recession after 2008, regression of the number of firearm certificates per 100,000 inhabitants on the year was performed with an autoregressive error model of first order to compare time trends before and after the legislation reform and following the 2008 economic recession.

Similarly, Poisson regression models were performed to compare the time trend in firearm suicides, the fraction of firearm suicides among all suicides, the total homicides (the sum of all convictions due to homicide and man slaughter) the number of firearm homicides, as well as the fraction of firearm homicides among all homicides, before and after the legislation was enacted and before and after 2008. The SAS procedure Genmod was used for this purpose. To allow for underdispersion in both models for firearm suicides, we allowed the variance estimate to depend on an underdispersion factor estimated from the data.

The regression model included linear time trends allowing for change points in 1998 and 2008. Changing population sizes were taken into account by including respective offsets into the model. To distinguish between the effects of the new legislation and other factors which are known to influence suicide and homicide rate, the unemployment rate and the average consumption of alcohol per capita were included into the analyses. The ratio of young men $(<20$ years of age $)$ in the population was included as a covariate in the regression model for homicides. The included parameters were chosen to ensure comparability with a previous study and due to a limited availability of variables from the national statistical bureau.

To facilitate a more detailed data analysis we have not examined differences in mean mortality rates of time periods but have examined their respective slopes for significant alterations in direction.

All parameter estimates are reported with 95\% confidence intervals. The analysis is based on firearm certificate numbers, suicide counts, firearm suicide counts, firearm homicide counts, and population numbers from 1985 to 2016. The two-sided significance level was set to $\leq 0.05$. Data analysis was conducted in SAS version 9.4 (SAS Institute Inc., Cary, NC, USA).

\section{Results}

\subsection{Firearm certificates}

In the years prior to the firearm legislation reform the number of new firearm certificates granted per 100,000 continuously increased, from 2632 in 1985 to 4526 in 1998. Following the legislation reform, the number of new certificates per 100,000 decreased to 2972 in 2008 and further decreased to 2692 in 2016. Significant positive autocorrelation was observed $(\mathrm{p}<0.0001)$.

For the number of firearm certificates per 100,000 a model with lag 1 autocorrelation and no confounders identified a significant increase of 141 additional certificates per year for the period of 1985-1998 (95\% CI [108,174], $\mathrm{p}<0.0001$ ) and a significant decrease of -132 per year for 1998-2008 (95\% CI [-171,-92], $p<0.0001$ ). For the period of 2008-2016 a significant decrease of

Table 1

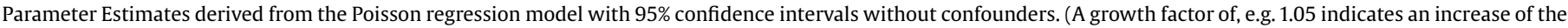
suicide rate by $5 \%$ per year).

\begin{tabular}{|c|c|c|c|c|c|}
\hline Variable & $\begin{array}{l}\text { Growth Factor } \\
\text { Before } 1998\end{array}$ & $\begin{array}{l}\text { Growth Factor } \\
\text { After } 1998\end{array}$ & $\begin{array}{l}\text { Percentage change of the } \\
\text { growth factor }\end{array}$ & $\begin{array}{l}\text { Growth Factor } \\
\text { After } 2008\end{array}$ & $\begin{array}{l}\text { Percentage change of the } \\
\text { growth factor }\end{array}$ \\
\hline Total number of Suicides & $0.976(0.973,0.981)$ & $\begin{array}{l}0.974(0.969 \\
0.978)\end{array}$ & $-0.3 \%(-1.0 \%, 0.5 \%)$ & $\begin{array}{l}0.990(0.984 \\
0.997)\end{array}$ & $1.7 \%(0.8 \%, 2.7 \%)$ \\
\hline Total number of Firearm Suicides & $1.000(0.994,1.006)$ & $\begin{array}{l}0.953(0.947 \\
0.960)\end{array}$ & $-4.7 \%(-5.7 \%,-3.6 \%)$ & $1.006(0.996,1.015)$ & $5.4 \%(3.9 \%, 7.0 \%)$ \\
\hline $\begin{array}{l}\text { Percentage of Firearm suicides among } \\
\text { all suicides }\end{array}$ & $1.024(1.018,1.030)$ & $\begin{array}{l}0.979(0.972 \\
0.986)\end{array}$ & $-4.4 \%(-5.4 \%,-3.3 \%)$ & $1016(1.006,1.026)$ & $3.8 \%(2.2 \%, 5.3 \%)$ \\
\hline Firearm Homicides & $0.998(0.973,1.023)$ & $\begin{array}{c}0.904 \\
(0.874,0.934)\end{array}$ & $-9.4 \%(-14.0 \%,-4.6 \%)$ & $1.023(0.972,1.076)$ & $13.2 \%(4.9 \%, 22.2 \%)$ \\
\hline $\begin{array}{l}\text { Percentage Firearm homicides among } \\
\text { all homicides }\end{array}$ & $1.060(1.032,1.087)$ & $\begin{array}{c}0.936 \\
(0.905,0.968)\end{array}$ & $-11.6 \%(-16.2 \%,-6.9 \%)$ & $1.010(1.045,1.157)$ & $17.5 \%(8.8 \%, 28.3 \%)$ \\
\hline
\end{tabular}




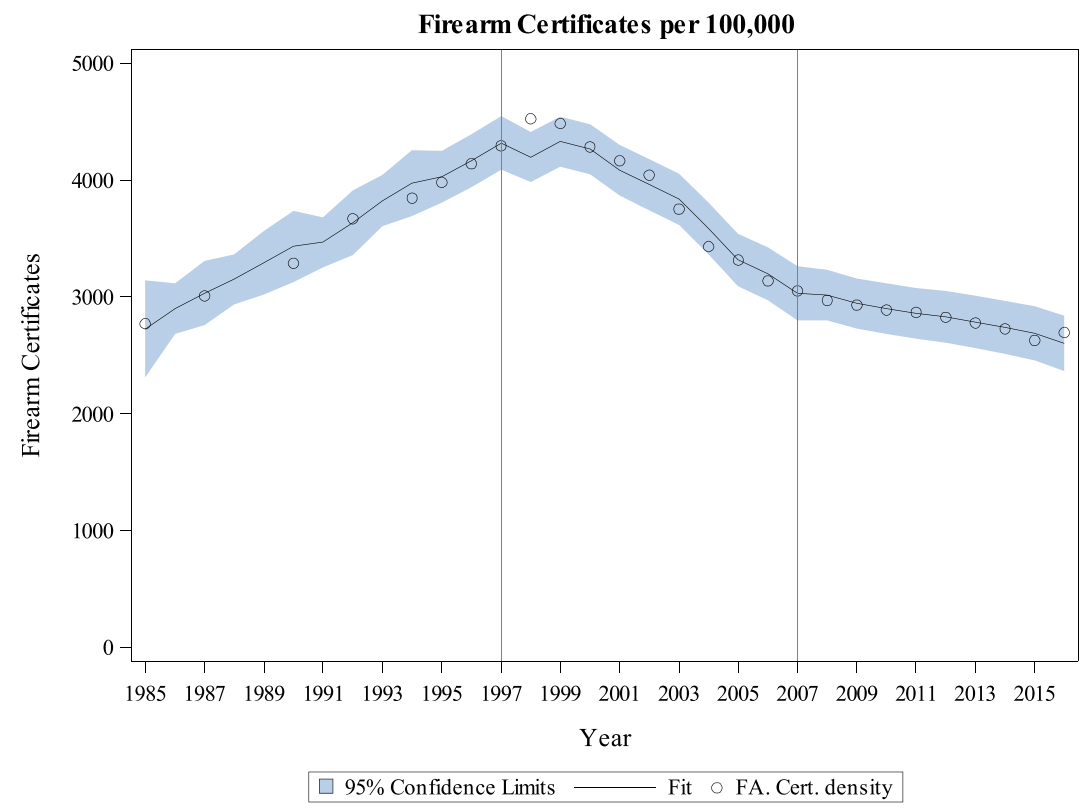

Fig. 1. Total number of Firearm certificates as observed and as predicted from the model without confounders (continuous line).

additional firearm certificates per 100,000 of -49 per year $(95 \% \mathrm{CI}$ $[-95,-3], \mathrm{p}=0.034)$ was found.

Both changes in trend were significant, with a trend decrease in 1998 , corresponding to a significant reversal of trend $(\mathrm{p}<0.0001)$ and a change in trend direction in 2008 showing a significant deceleration of the decrease of the firearm certificates per 100,000 per year $(p=0.027)$ (see Fig. 1 ).

Neither unemployment rate $(p=0.954)$ nor alcohol consumption per capita $(\mathrm{p}=0.978)$ had significant effects on firearm certificates per 100,000 . Firearm certificate trends (both positive and negative) were unaffected by confounders. The inclusion of these confounders did not affect the trend change in 1998 ( $p<0.0001)$. It did, however, alter the significance of trend change in $2008(\mathrm{p}=0.058)$.

\subsection{Total suicide rates}

The total suicide rates per 100,000 for the Austrian population decreased from 27.6 in 1985 to 19.6 in 1998. Thereafter, the trend continued and the total suicide rate decreased to 15.2 in 2008 . In the following years the total suicide rate remained relatively stable (with 13.8 per 100,000 in 2016). No significant autocorrelation was found in the time series $(\mathrm{p}=0.093)$.

In a model without confounders, Negative Binominal Regression identified a significant decrease of the total suicide rates per 100,000 between 1985 and 1998 of $-2.4 \%$ per year ( $95 \%$ CI $[-2.8 \%$, $-2.0 \%$ ], $\mathrm{p}<0.0001$ ), as well as between 1998 and 2008 with $-2.7 \%$ per year $(95 \% \mathrm{CI}[-3.1 \%,-2.2 \%], \mathrm{p}<0.0001)$. After 2008 , the annual decrease of total suicide rates per 100,000 decelerated, but still remained significant at $-1 \%(95 \%$ CI $[-1.6 \%,-0.3 \%]$, $\mathrm{p}=0.028$ ).

No significant change in trend was observed in $1998(\mathrm{p}=0.412)$, but a significant positive change in trend for 2008 was found $(p=0.001)$ showing a significant deceleration of the decrease for the total suicide rate per 100,000 (see Fig. 2).

Neither unemployment rates (est: $-0.4 \%, 95 \% \mathrm{CI}[-3.4 \%, 2.6 \%]$, $\mathrm{p}=0.767$ ) nor alcohol consumption per capita (est: $-2.9 \%, 95 \% \mathrm{CI}$ [ $-7.1 \%, 1.5 \%], \mathrm{p}=0.190$ ) had significant effects on total suicide rates per 100,000 . After inclusion of these confounders into the model, the decrease of the total suicide rate per 100,000 1985-1998 and 1998-2008 remained significant ( $\mathrm{p}<0.0001$ for both periods), but no significant trend was observed for the period 2008-2016 $(p=0.079)$. Significances of the changes of trend for the years 1998 and 2008 are similar to those in the model without confounders (1998: $\mathrm{p}=0.325 ; 2008$ : $\mathrm{p}=0.004$ ).

\subsection{Firearm suicide rates}

The firearm suicide rate per 100,000 for the Austrian population was relatively stable in the years between 1985 and 1998 (1985: 4.0 ; 1998: 3.7). Following the firearm legislation reform in 1997 the total firearm suicide rate decreased down to its lowest rate in 2008 with 2.4 per 100,000 . Thereafter there was no excessive fluctuation in the total firearm suicide rate (min-max: $2.4-2.7$ ).

For the total firearm suicide rates per 100,000, Negative Binominal Regression identified in a model without confounders no trend between 1985 and 1998 (95\% CI [- 0.6\%, 0.6\%], p = 0.990), a significant decrease of $-4.7 \%$ per year between 1998 and 2008 (95\% CI $[-5.3 \%,-4.0 \%], \mathrm{p}<0.0001)$, and a non-significant increase of $0.5 \%$ per year between 2008 and 2016 (95\% CI [-0.4\%, 1.5\%], $\mathrm{p}=0.266$ ). Both changes in time trends were significant (1998: $\mathrm{p}<0.0001$; 2008: $\mathrm{p}<0.0001$ ) (see Fig. 3).

Neither unemployment rates (est: $0.4 \%, 95 \%$ CI [- 3.8\%, 4.7\%], $\mathrm{p}=0.865$ ) nor alcohol consumption per capita (est: $4.9 \%, 95 \% \mathrm{CI}$ [- 1.5\%, 11.6\%], $\mathrm{p}=0.136$ ) had significant effects on the model outcome, and inclusion of confounders showed no influence on the significance of the models trends or trend changes.

\subsection{Fraction of firearm suicides among all suicides}

In the period 1985-1998 the fraction of firearm suicides among all suicides (calculated as a percentage of firearm suicides within total number of suicides) increased from $14.3 \%$ to $18.7 \%$. Following the firearm legislation reform, the fraction of firearm suicides among all suicides decreased to $15.5 \%$ in 2008 . Thereafter, it again increased to $17.7 \%$ in 2016.

For the fraction of firearm suicides among all suicides, Poisson regression in a model without confounders identified a significant increase of 2.4\% per year between 1985 and 1998 (95\% CI [1.8\%, $3.0 \%$ ], $\mathrm{p}<0.0001$ ), a significant decrease of $-2.1 \%$ per year between 1998 and 2008 (95\% CI [ $-2.8 \%,-1.4 \%], \mathrm{p}<0.0001)$, and a significant increase of $1.6 \%$ per year between 2008 and 2016 (95\% 


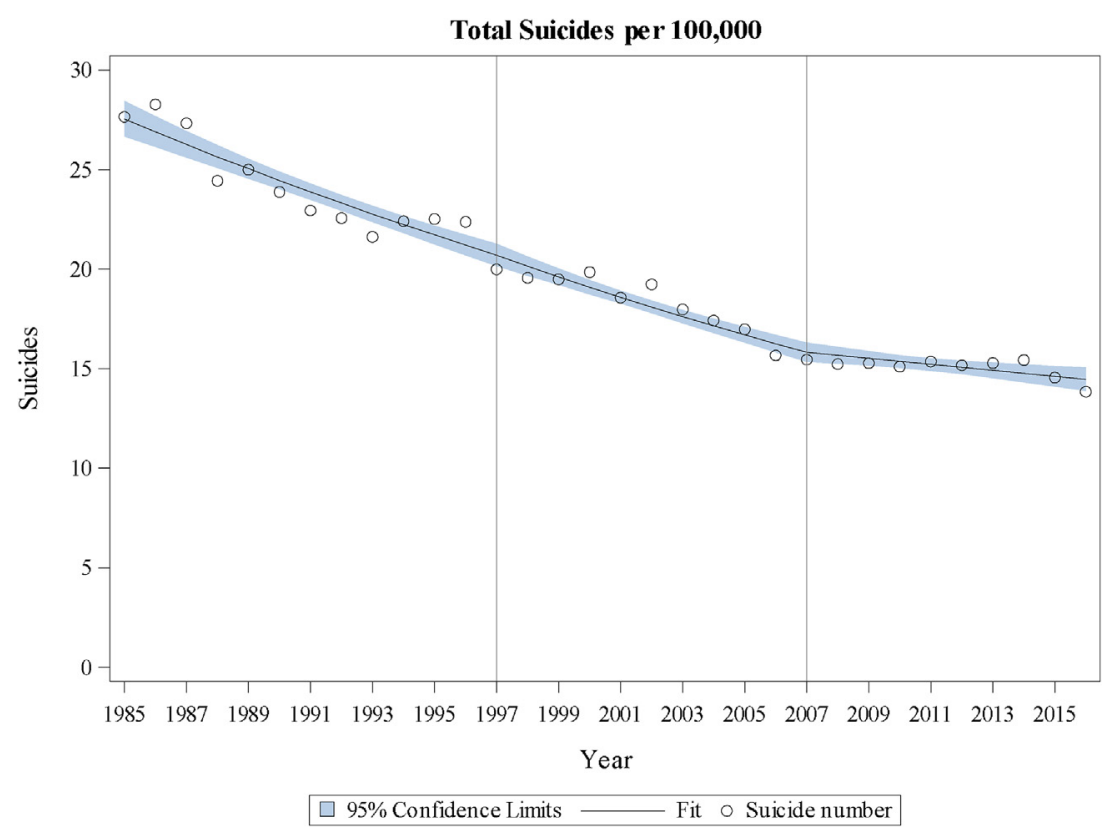

Fig. 2. Suicide mortality rate per 100,000 per year with $95 \%$ confidence intervals. Showing a significant change in rate for 2008 .

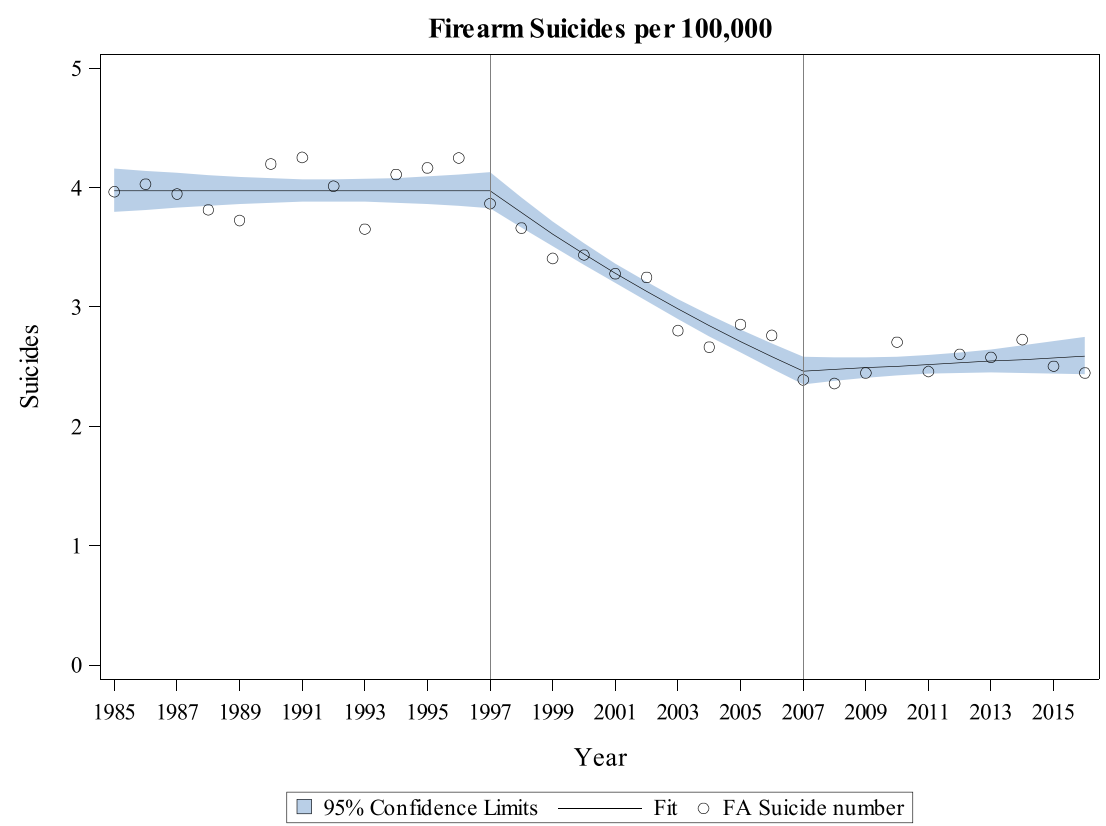

Fig. 3. Firearm suicides per 100,000 per year with $95 \%$ confidence intervals. Showing a significant change in rate for both 1998 and 2008.

CI $[0.5 \%, 2.1 \%], \mathrm{p}=0.002)$. Both changes in trend were significant (1998: $\mathrm{p}<0.0001 ; 2008$ : $\mathrm{p}<0.0001$ ) (see Fig. 4).

Alcohol consumption per capita had a significant positive effect (7.9\%, 95\% CI [1.7\%, 14.4\%], p=0.011) while unemployment rates showed no significant effect (est: 0.9\%, 95\% CI [- 3.0\%, 5.0\%], $\mathrm{p}=0.654)$. After inclusion of both confounders, the increases (1985-1998: $\mathrm{p}<0.0001 ; 2008-2016: \mathrm{p}=0.040)$, as well as the decrease (1998-2008: $p=0.003)$, in fraction of firearm suicides among all suicides remain significant. Furthermore, both changes of trend remain significant (1998: $\mathrm{p}<0.0001 ; 2008$ : $\mathrm{p}=0.009$ ).

\subsection{Total homicide rates}

The total homicide rate for the Austrian population decreased from 10.0 in 1985 to 4.4 per 100,000 in 1998 . Thereafter the trend continued and the total homicide rate was 3.4 in 2008 and decreased further to 1.9 in 2016 . No significant autocorrelation was found $(\mathrm{p}=0.627)$.

In a model without confounders, Negative Binominal Regression identified a significant decrease of the total homicide rates between 1985 and 1998 of $-5.8 \%$ per year (95\% CI [ - 6.5\%, - 5.0\%], $\mathrm{p}<0.0001)$ as well as between 1998 and 2008 with $-3.4 \%$ per year (95\% CI [-4.4\%, - 2.5\%], p < 0.0001).

A significant positive change in trend was observed in 1998 $(p=0.003)$, showing a deceleration of the decrease for the total homicide rate. For 2008 our model identified a significant change in trend $(p=0.008)$ showing an acceleration of the decrease of total homicide rate (see Fig. 5).

Neither unemployment rates (est: $-0.4 \%, 95 \% \mathrm{CI}[-4.9 \%, 4.4 \%]$, $\mathrm{p}=0.879$ ) nor proportion of young males (est: $-13.1 \%, 95 \% \mathrm{CI}$ 


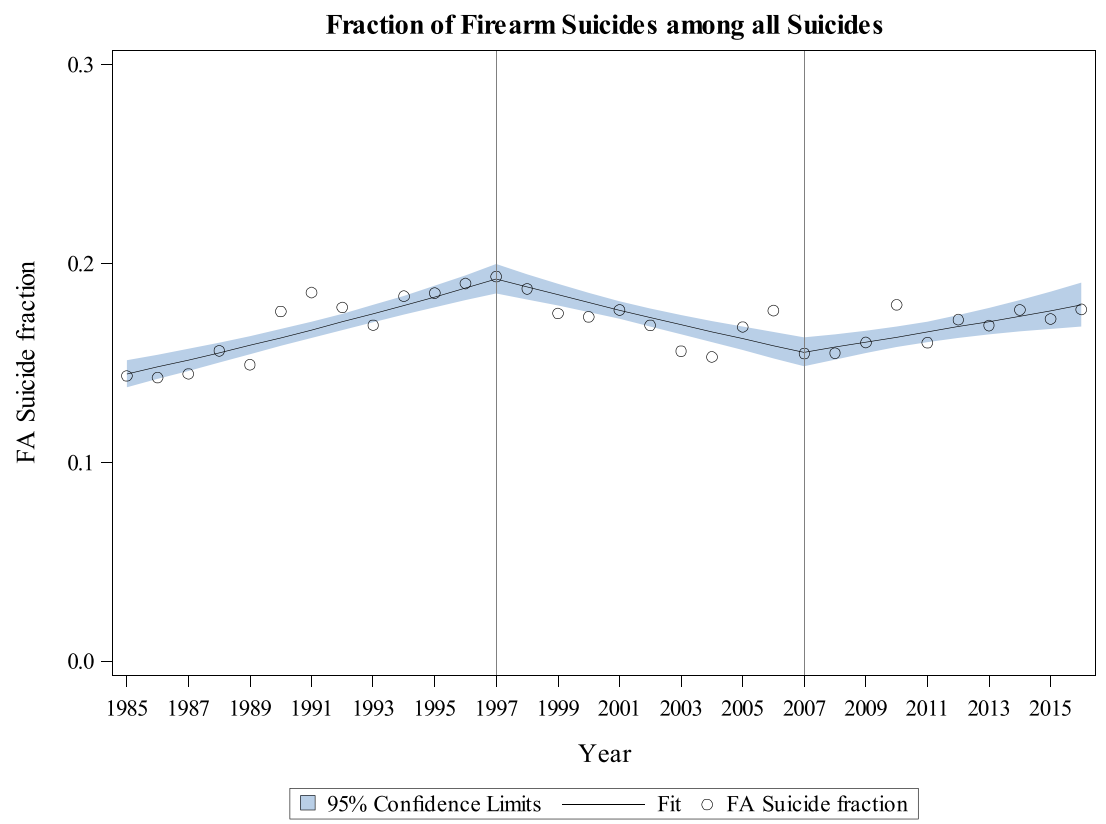

Fig. 4. Fraction of firearm suicides among suicides per year with $95 \%$ confidence intervals. Showing a significant change in rate for both 1998 and 2008.

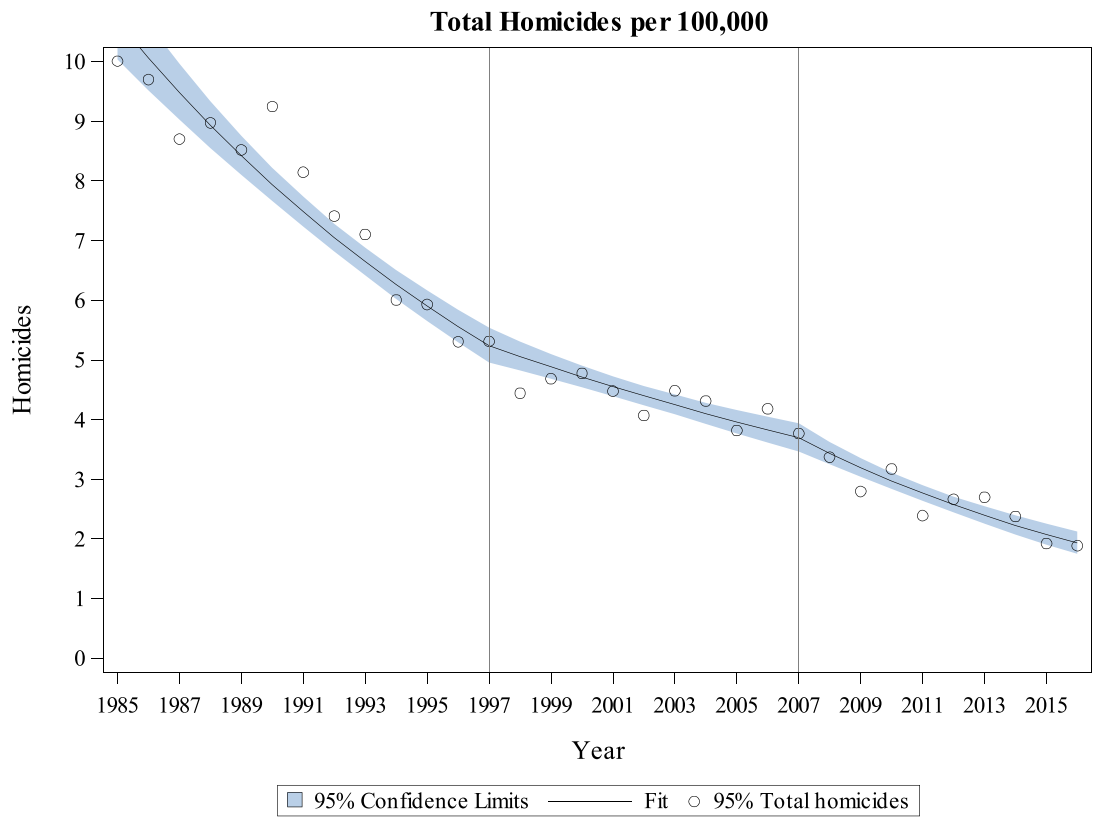

Fig. 5. Total homicides per 100,000 per year with 95\% confidence intervals. Showing a significant change in rate for both 1998 and 2008.

$[-25.9 \%, 1,8 \%], p=0.082$ ) had significant effects on the total homicide rates. In contrast, alcohol consumption per capita (est: $9.1 \%, 95 \% \mathrm{CI}[0.1 \%, 19.0 \%], \mathrm{p}=0.048$ ) had a significant positive effect on total homicide rate. After exclusion of unemployment rate and proportion of young men, alcohol showed a highly significant positive correlation with total homicide rates (est: $15.5 \%, 95 \% \mathrm{CI}$ [7.9\%, 22.6\%], $\mathrm{p}<0.0001$ ). After inclusion of alcohol into the model, the decrease of the total homicide rate remained significant ( $p<0.0001$ for all three periods) and all changes remained significant ( $\mathrm{p}<.0001$ for both time points).

\subsection{Firearm homicide rates}

In the period 1985-1998 the firearm homicide rates per 100,000 remained constant at 0.4 per 100,000 (fluctuating between 0.3 and 0.5 ). Following 1998, the rate decreased to 0.1 per 100,000 per year until 2008. Between 2008 and 2016 the firearm homicide rate per 100,000 increased to 0.2 per year. For the firearm homicide rates per 100,000 per year, Poisson Regression in a model without confounders identified a nonsignificant decrease of $-0.2 \%$ per year between 1985 and 1998 (95\% CI [- 2.7\%, 2.3\%], p = 0.865) and a significant decrease of $-9.6 \%$ for the period of 1998 until 2008 (95\% CI [- 12.6\%, - 6.6\%], p $<0.0001)$. For the years 2008 until 2016 we found a nonsignificant increase of $2.3 \%$ per year (95\% CI [- 2.7\%, 7.6\%], p=0.376). Both changes in trend were significant (1998: $p=0.0002,2008$ : $\mathrm{p}=0.002$ ) (see Fig. 6).

None of the confounders showed significant effects (Unemployment rate: est: 7.5\%, 95\% CI [- 12.5\%, 32.2\%], p = 0.492; alcohol consumption per capita: est: $33.4 \%, 95 \%$ CI [- 8.6\%, 94.4\%], $\mathrm{p}=0.135$, proportion of young men: est: $-0.3 \%, 95 \% \mathrm{CI}[-50.3 \%$, $99.8 \%$ ], $\mathrm{p}=0.992$ ) on firearm homicide rates per 100,000 . 


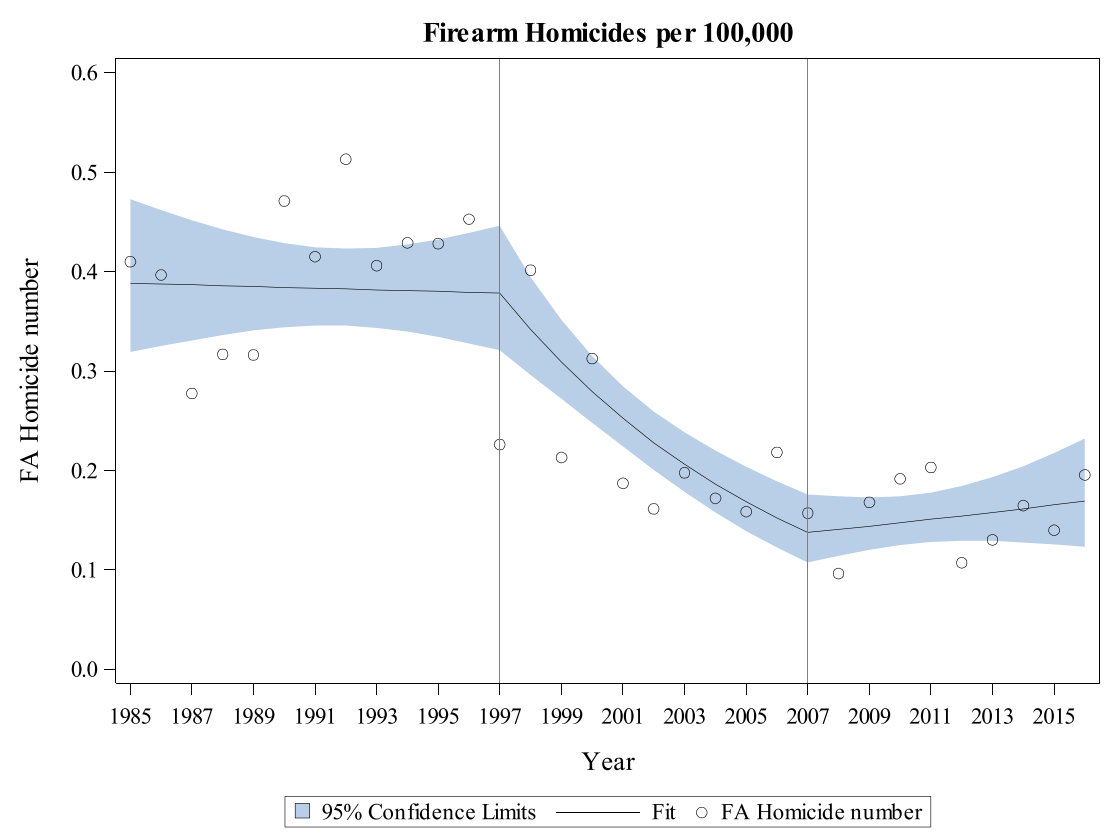

Fig. 6. Firearm homicides per 100,000 per year with 95\% confidence intervals. Showing a significant change in rate for both 1998 and 2008.

After inclusion of the confounders, neither the time trends (1985-1998: $\quad \mathrm{p}=0.980 ;$ 1998-2008: $\mathrm{p}=0.147 ; \quad 2008-2016$ : $\mathrm{p}=0.928$ ), nor the changes in the time trends remained significant (1998: $\mathrm{p}=0.069 ; 2008: \mathrm{p}=0.190$ ).

\subsection{Fraction of firearm homicides among all homicides}

In the period 1985-1998 the fraction of firearm homicides among all homicides (calculated as a percentage of firearm homicides within total number of homicides) increased from $4.1 \%$ to $9.0 \%$. Following the firearm legislation reform, the fraction of firearm homicides among all homicides decreased to $2.9 \%$ in 2008. Thereafter it again increased to $10.4 \%$ in 2016 .

For the fraction of firearm homicides among all homicides, Poisson regression identified in a model without confounders a significant increase of 6.0\% per year between 1985 and 1998 (95\%
$\mathrm{CI}$ [3.3\%, 8.7\%], $\mathrm{p}<0.0001$ ), a significant decrease of $-6.4 \%$ per year between 1998 and 2008 (95\% CI [- 9.5\%, - 3.2\%], p < 0.0001) and a significant increase of $10.0 \%$ per year between 2008 and 2016 (95\% $\mathrm{CI}[4.5 \%, 15.7 \%], \mathrm{p}=0.0003)$. Both changes in trend were significant (1998: $\mathrm{p}<0.0001$; 2008: $\mathrm{p}<0.0001$ ) (see Fig. 7).

Neither alcohol consumption (est: $23.0 \%, 95 \%$ CI $[-17.6 \%$, 83.7\%], $\mathrm{p}=0.311$ ) nor unemployment rates (est: $-8.3 \%, 95 \% \mathrm{CI}$ [ $-13.1 \%, 35.0 \%], \mathrm{p}=0.477$ ) nor proportion of young males (est: $17.6 \%, 95 \% \mathrm{CI}[-43.8 \%, 146.2 \%], \mathrm{p}=0.667$ ) had significant effects on the fraction of firearm homicides among all homicides (Table 1).

\section{Discussion}

In agreement with the availability hypothesis, our previous results have shown [9] that a significant reduction of the mortality rate for suicides and homicides by firearms in Austria followed a



Fig. 7. Fraction of firearm homicides among homicides per year with $95 \%$ confidence intervals. Showing a significant change in rate for both 1998 and 2008. 
significant reduction of the availability of firearm certificates after the 1997 legislation reform. In the current 20-year follow-up, we are able to corroborate previous results. After a decreased availability of firearms in the Austrian population, a further significant reduction of the overall suicide rate, the firearm suicide rate, proportion of firearm suicide among suicides, and firearm homicides can be observed. However, this decline of firearm availability significantly changed its trend after the year 2008, which coincided with the onset of the global economic crisis. Shortly after stabilization of the financial crisis in Europe, Austria and many other European countries faced an influx of refugees from destabilized regions and war zones. Subsequently, public media reports pointed to increased firearm purchases in the general population [13].

Following 2008, a significant trend change in the total suicide rate, the firearm suicide rate, the fraction of firearm suicide among all suicides, the total homicide rate, the firearm homicide rate as well as the fraction of firearm homicide among all homicides in Austria were observable. As previously shown, there was a significant increase in global suicide rates following the global financial crisis [14]. While the United States already faced increasing total suicide rates prior to 2008, this trend accelerated further afterwards. In contrast, Canada and Europe have been, consistent with Austrian data, experiencing downward trends of total suicide rates prior to 2008 [14]. An analysis of 20 European countries showed suicide rates of men had significantly increased following the financial crisis in Europe and were not affected by the spending on suicide prevention or antidepressants prescribed [15]. These results were supported by independent analyses, showing increases in total suicide rates, particularly among young men, and their positive associations with rising unemployment rates and inflation, or their inverse relationships with GDP and national growth rates during the economic crisis $[16,17]$.

\subsection{General effects of the firearm legislation reform}

\subsubsection{Firearm certificates}

As previously reported, while an increase of firearm certificates was observable prior to the firearm legislation reform in 1997, as was a significant reduction of firearm certificates between 1998 and 2005 [9]. In the present report, a further significant declining trend in firearm certificates until 2008 was observed. After 2008, presumably due to the onset of the economic crisis, a significant change in the trend of firearm certificates was registered. While the data still shows a decline in the number of newly issued firearm certificates, the decrease significantly decelerated, leading to a higher than expected availability of firearms in the population and a higher number of total firearm certificates and thus firearms in the population.

\subsubsection{Firearm suicide rates}

As firearms became less available for the population after the firearm legislation reform in 1997, we observed a decrease of the firearm suicide rates. Both, the decreasing trend after 1998 as well as the trend change in 1998 were significant. After 2008, the firearm suicide trend significantly changed again; the higher than expected availability of firearms coincided with a significant change in the trend of firearm suicide rates. These changes in the trends were significant even after known risk factors for suicide such as per capita consumption of alcohol or the unemployment rate were adjusted for - thus supporting the availability of firearms as being an independent risk factor for firearm suicide in a given population. This finding is in agreement with a large body of previous results [1,4,5,7,18-28].

\subsubsection{Fraction of firearm suicides among all suicides}

In the years prior to 1998, a significant increase in the fraction of firearm suicides among all suicides was observed. As the firearm suicide rate decreased thereafter, so did the percentage of firearm suicides among all suicides. While unemployment rate showed no effect on the fraction of firearm suicides among all suicides, alcohol consumption did show a significant positive correlation with the fraction of firearm suicides among all suicides. An increase of suicides and its significant positive correlation with alcohol consumption is in agreement with the proposed impact of impulsivity on suicidal behaviour $[29,30]$. The fraction of firearm suicides among all suicides significantly decreased following a more restrictive firearm legislation in 1997 and the trend of the total suicide rate of the population itself showed no significant change at the same point in time; this can be interpreted as a possible direct effect of the legislation and the restriction of availability. This is in agreement with available literature $[1,7,19,21,22]$. Correspondingly, the increase in firearm certificates after 2008 coincides with a significant increase of the fraction of firearm suicides among all suicides.

\subsubsection{Total homicide rate}

The total homicide rate in Austria already showed a declining trend prior to the firearm legislation reform in 1997. Interestingly, the decrease of the total homicide rate slowed down following the firearm legislation reform in 1997 and accelerated after the onset of crisis in 2008. This finding seems counterintuitive and worth further analyses. Data from Australia, Norway and the United States has shown that firearm legislation reforms are associated with a reduction of the total homicide rate $[5,7,8,24,28,31]$. As with the fraction of firearm suicides among all suicides, the total homicide rate was significantly affected by the alcohol consumption per capita. This is in agreement with the aforementioned hypothesis of alcohol acting as a disinhibiting agent.

\subsubsection{Firearm homicide rate}

Following a more restrictive firearm legislation, a significant reduction in firearm homicide rate was observed after 1998. However, this decline significantly changed its trend after 2008. Similar results have been published for Norway [8] and the United States [5] after introduction of stricter firearm legislation. Conversely, after the Stand Your Ground law was passed in Florida, reflecting an introduction of a more lenient firearm legislation, a significant increase in firearm homicide rate was documented [31]. However, inconclusive results on the possible effects of firearm legislation reform were observed in Australia, where the firearm homicide rate, in contrast to the total homicide rate, showed no significant change [7,24]. In general, following the primum non nocere rule, it can be concluded that more restrictive firearm legislation does no harm - there are, to the best of our knowledge, no studies reporting increasing firearm deaths after legislative restrictions or enacted interventions targeted to reduce firearm availability.

\subsubsection{Fraction of firearm homicides among all homicides}

Prior to the firearm legislation reform, a significant increase of the fraction of firearm homicides among all homicides was observable in our data. In agreement with the availability hypothesis, the fraction of firearm homicides among all homicides significantly decreased following a reduction of available firearms in the Austrian population. As firearms once again were more available within the population, our model showed a stark and significant increase in the fraction of firearm homicides among all homicides. These changes were independent of the total homicide rate, for which opposing trend changes and trends were observable. This data is in agreement to our findings for the fraction of firearm suicides among all suicides. Both results further strengthen the availability hypothesis. 


\subsection{Change in the total suicide rate}

As already shown, suicide rates in Austria were declining prior to the firearm legislation reform in 1997 and continued to decline thereafter. This is in agreement with declines in total suicide rates among several other European countries during mid 1980ies $[14,18,32]$. Austria has been primarily perceived as a country in which suicide rates were not influenced by the economic recession and Austria's strong social security network has been suggested to account for the decrease in suicides, despite rising unemployment [33]. However, after presenting updated data until 2016, this observation needs to be revised since there was a significant trend change in the total suicide rate in 2008 in Austria.

The documented decline of overall suicide rates in Austria until 1998 is still not well understood but seems to be associated with a significant development of the psychosocial system, including an increasing availability of mental health professionals [34,35]. The current observed increase in the trend of firearm suicide and the deceleration of the decrease of total suicide rates after 2008 are worth further consideration. Changing societal circumstances such as the economic or refugee crises might influence suicide rates and the suicide method choice in complex ways. Although the Austrian situation, due to its naturalistic firearm suicide prevention experiment, allows some hypotheses to be generated, the complex multidimensional interplay between suicide risk and protective factors in a country remains a methodological challenge for research.

With regard to the decrease of total suicide rates following a firearm legislation reform, our results are in agreement with numerous studies [1,18,21-23,25-27,36-38]. However, some researchers have reported no difference in trend of the total suicide rate before and after legislation reform was implemented $[6,19,39]$ and in one study such a difference in trend was observable only for the male population [4]. Importantly, as far as we know, no prior research has documented a harmful increase of total suicide rates after the enactment of more restrictive firearm legislation.

\section{Limitations of this study}

Several limitations of this study need to be addressed. The significant changes in rates of firearm suicide and homicide observed here may be attributable to factors not included in our data set. While we corrected in part for this by covariates such as per capita alcohol per capita consumption or the unemployment rate, other factors might have been missed. We are aware that officially granted firearm certificates can underrepresent the actual number of available firearms available in the population. However, in contrast to other reports, our study was not based on survey data to create proxy variables for the number of firearms in the population. As we rely on population data, no direct conclusions about individuals can be drawn and causal interpretations should be drawn with caution, although our data study design allows to judge several epidemiological criteria for causality [40].

\section{Conclusions}

Our results revealed that a decrease in firearm certificates, following the firearm legislation reform in 1997, coincided with a reduction of rates of suicide and homicide by firearms. However, in recent years, the effective firearm legislation has been counteracted by societal changes, presumably the economic and refugee crisis after 2008, leading to a relative increase in firearm availability, firearm suicide rates and the total suicide rate. Borrowing from the understanding of physiological processes, an adaptive process seems to have taken place at the societal level in Austria which needs appropriate counter-interventions consistent with a complex social-ecological understanding of suicide prevention and further efforts to reduce firearm availability [41].

We suggest that examining data for trend changes is more informative than, as performed by other studies, the calculation of differences in means between time periods or trends before and after a legislation reform. The latter approach may obscure important trend changes [7].

This study benefits from the existance of an Austrian federal registry of firearm possession. Such a federal electronic registry is unavailable in many countries and has, for decades, hampered firearm death research and prevention efforts. From the perspective of research, the official monitoring of firearm availability as a mediator in a causative chain of firearm deaths [42] is of crucial importance. The lack of such data on firearm possession might be seen as a reflection of a governmental neglect of this important issue.

\section{Conflict interest}

None.

\section{Funding}

This research did not receive any specific grant from funding agencies in the public, commercial, or not-for-profit sectors.

\section{References}

[1] Anestis M.D., Anestis JC. Suicide rates and state laws regulating access and exposure to handguns. Am J Public Health 2015;105(10):2049-58.

[2] Fleegler EW, Lee LK, Monuteaux MC, Hemenway D, Mannix R. Firearm legislation and firearm-related fatalities in the United States. JAMA Intern Med 2013;173(9):732-40.

[3] E.J. Kaufman, C.N. Morrison , C.C. Branas , D.J. Wiebe . State firearm laws and interstate firearm deaths from homicide and suicide in the United States: a cross-sectional analysis of data by county JAMA Intern Med 2018; ePub ahead of print on 5th of March 2018

[4] Siegel M, Rothman EF. Firearm Ownership and Suicide Rates Among US Men and Women, 1981-2013. Am J Public Health 2016;106(7):1316-22.

[5] Loftin C, McDowall D, Wiersema B, Cottey TJ. Effects of restrictive licensing of handguns on homicide and suicide in the District of Columbia. N Eng J Med 1991;325(23):1615-20.

[6] Klieve H, Barnes M, De Leo D. Controlling firearms use in Australia: has the 1996 gun law reform produced the decrease in rates of suicide with this method? Soc Psychiatry Psychiatr Epidemiol 2009;44(4):285-92.

[7] Chapman S, Alpers P, Jones M. Association between gun law reforms and intentional firearm deaths in Australia, 1979-2013. JAMA 2016;316(3):291-9.

[8] Gjertsen F, Leenaars A, Vollrath ME. Mixed impact of firearms restrictions on fatal firearm injuries in males: a national observational study. Int J Environ Res Public Health 2013;11(1):487-506.

[9] Kapusta ND, Etzersdorfer E, Krall C, Sonneck G. Firearm legislation reform in the European Union: impact on firearm availability, firearm suicide and homicide rates in Austria. Br J Psychiatry 2007;191:253-7.

[10] Karanikolos M, Heino P, McKee M, Stuckler D, Legido-Quigley H. Effects of the global financial crisis on health in high-Income oecd countries: a narrative review. Int J Health Serv 2016;46(2):208-40.

[11] Varvin S. Our relations to refugees: between compassion and dehumanization. Am J Psychoanal 2017:77(4):359-77.

[12] Ferwerda J, Flynn DJ, Horiuchi Y. Explaining opposition to refugee resettlement: the role of NIMBYism and perceived threats. Sci Adv 2017;3 (9):e1700812.

[13] Pittner R. Waffen zur Selbstverteidigung boomen [Newspaper]. 2018 Kurier: Kurier; 2015 [updated 28.10.2015; cited 2017 17.12.2017]. Available from: https://kurier.at/amp/chronik/oesterreich/waffen-zur-selbstverteidigungboomen/160.775.850.

[14] Reeves A, McKee M, Stuckler D. Economic suicides in the great recession in Europe and North America. Br J Psychiatry 2014;205(3):246-7.

[15] Reeves A, McKee M, Gunnell D, Chang SS, Basu S, Barr B, et al. Economic shocks, resilience, and male suicides in the Great Recession: cross-national analysis of 20 EU countries. Eur J Public Health 2015;25(3):404-9.

[16] Chang SS, Stuckler D, Yip P, Gunnell D. Impact of 2008 global economic crisis on suicide: time trend study in 54 countries. BMJ (Clin Res Ed) 2013·347:f5239.

[17] Fountoulakis KN, Kawohl W, Theodorakis PN, Kerkhof AJ, Navickas A, Hoschl C et al. Relationship of suicide rates to economic variables in Europe: 2000-2011. Br J Psychiatry 2014;205(6):486-96.

[18] Reisch T, Steffen T, Habenstein A, Tschacher W. Change in suicide rates in Switzerland before and after firearm restriction resulting from the 2003 Army XXI reform. Am J Psychiatry 2013;170(9):977-84. 
[19] Beautrais AL, Fergusson DM, Horwood LJ. Firearms legislation and reductions in firearm-related suicide deaths in New Zealand. Aust N Z J Psychiatry 2006;40(3):253-9.

[20] Miller M, Warren M, Hemenway D, Azrael D. Firearms and suicide in US cities. Inj Prev 2015;21(e1):e116-9.

[21] Anestis M, Capron DW. The associations between state veteran population rates, handgun legislation, and statewide suicide rates. J Psychiatr Res 2016;74:30-4.

[22] Anestis MD, Khazem LR, Law KC, Houtsma C, LeTard R, Moberg F, et al. The association between state laws regulating handgun ownership and statewide suicide rates. Am J Public Health 2015;105(10):2059-67.

[23] Lubin G, Werbeloff N, Halperin D, Shmushkevitch M, Weiser M, Knobler HY. Decrease in suicide rates after a change of policy reducing access to firearms in adolescents: a naturalistic epidemiological study. Suicide Life Threat Behav 2010;40(5):421-4.

[24] Chapman S, Alpers P, Agho K. Jones M Australia's 1996 gun law reforms: faster falls in firearm deaths, firearm suicides, and a decade without mass shootings. Inj Prev 2015;21(5):355-62.

[25] Miller M, Barber C, White RA, Azrael D. Firearms and suicide in the United States: is risk independent of underlying suicidal behavior? Am J Epidemiol 2013;178(6):946-55.

[26] Miller M, Azrael D, Hepburn L, Hemenway D, Lippmann SJ. The association between changes in household firearm ownership and rates of suicide in the United States, 1981-2002. Inj Prev 2006;12(3):178-82.

[27] Miller M, Lippmann SJ, Azrael D, Hemenway D. Household firearm ownership and rates of suicide across the 50 United States. J Trauma 2007;62(4)1029-34 discussion 34-5.

[28] Ludwig J, Cook PJ. Homicide and suicide rates associated with implementation of the Brady Handgun Violence Prevention Act. JAMA 2000;284(5):585-91.

[29] Simon OR, Swann AC, Powell KE, Potter LB, Kresnow MJ, O'Carroll PW. Characteristics of impulsive suicide attempts and attempters. Suicide Life Threat Behav 2001;32(Suppl. 1):49-59.
[30] Miller M, Hemenway D. Guns and suicide in the United States. N Eng J Med 2008;359(10):989-91.

[31] Humphreys DK, Gasparrini A, Wiebe DJ. Evaluating the impact of florida's stand your ground self-defense law on homicide and suicide by firearm: an interrupted time series study. JAMA Intern Med 2017;177(1):44-50.

[32] Nordentoft M, Qin P, Helweg-Larsen K, Juel K. Time-trends in method-specific suicide rates compared with the availability of specific compounds. The Danish experience. Nord J Psychiatry 2006;60(2):97-106.

[33] Stuckler D, Basu S, Suhrcke M, Coutts A, McKee M. Effects of the 2008 recession on health: a first look at European data. Lancet 2011;378(9786):124-5.

[34] Vyssoki B, Willeit M, Bluml V, Hofer P, Erfurth A, Psota G, et al. Inpatient treatment of major depression in Austria between 1989 and 2009: impact of downsizing of psychiatric hospitals on admissions, suicide rates and outpatient psychiatric services. J Affect Disord 2011;133(1-2):93-6.

[35] Kapusta ND, Niederkrotenthaler T, Etzersdorfer E, Voracek M, Dervic K, JandlJager E, et al. Influence of psychotherapist density and antidepressant sales on suicide rates. Acta Psychiatr Scand 2009;119(3):236-42.

[36] Crifasi CK, Meyers JS, Vernick JS, Webster DW. Effects of changes in permit-topurchase handgun laws in Connecticut and Missouri on suicide rates. Prev Med 2015;79:43-9.

[37] Qi X, Hu W, Page A, Tong S. Dynamic pattern of suicide in Australia, 1986-2005: a descriptive-analytic study. BMJ Open 2014;4(7):e005311.

[38] Conner KR, Zhong Y. State firearm laws and rates of suicide in men and women. Am J Prev Med 2003;25(4):320-4.

[39] Gagne M, Robitaille Y, Hamel D, St-Laurent D. Firearms regulation and declining rates of male suicide in Quebec. Inj Prev 2010;16(4):247-53.

[40] Bradford Hill A. The environment and disease association or causation? Proc R Soc Med 1965;58(5):295-300.

[41] Cramer RJ, Kapusta ND. A social-Ecological framework of theory, assessment, and prevention of suicide. Front Psychol 2017;8:1756.

[42] Kapusta ND, Cramer RJ. Firearm suicide in the United States from a broader preventive perspective. Am J Psychiatry 2017;174(1):77-8. 